\title{
Injury and Illness Rates During Ultratrail Running
}

Authors

Affiliations

\author{
G. Vernillo ${ }^{1,3}$, A. Savoldelli ${ }^{2,3}$, A. La Torre ${ }^{1}$, S. Skafidas ${ }^{4}$, L. Bortolan ${ }^{2,3}$, F. Schena ${ }^{2,3}$
}

Affiliation addresses are listed at the end of the article
Key words

- dermatological injuries

- injury management

- musculoskeletal injuries

- trail running

- ultraendurance

- ultramarathon accepted after revision November 23, 2015

\section{Bibliography}

DOI http://dx.doi.org/

10.1055/s-0035-1569347

Published online:

April 26, 2016

Int J Sports Med 2016; 37:

565-569 @ Georg Thieme

Verlag KG Stuttgart · New York

ISSN 0172-4622

Correspondence

\section{Gianluca Vernillo, PhD}

Department of Biomedical Sciences for Health, Università degli Studi di Milano

via Antonio Kramer, 4/a, 20133

Milan - Italy

Tel.: + 39.02.50.31.51.59

Fax: + 39.02.50.31.51.59

gianluca.vernillo@unimi.it

\section{Abstract}

$\nabla$

This study aimed to describe injury/illness rates in ultratrail runners competing in a 65-km race to build a foundation for injury prevention and help race organizers to plan medical provision for these events. Prospectively transcribed medical records were analysed for 77 athletes at the end of the race. Number of injuries/illnesses per 1000 runners and per 1000 -h run, overall injury/illness rate and $90 \%$ confidence intervals and rates for major and minor illnesses, musculoskeletal injuries, and skin disorders were analysed. A total of 132 injuries/illnesses were encountered during the race. The overall injuries/illnesses were

\section{Introduction}

$\nabla$

During the past few years, the popularity of ultratrail running (UTR) races has grown alongside that of ultramarathon races $[10,12]$. UTR can be defined as any event longer than the marathon distance $(42.195 \mathrm{~km})$ performed in a mountain context, on rough terrain and involving an elevation change [27-29]. Hoffman et al. found that there was a $5200 \%$ increase in the number of UTR races between 1978 and 2008 [12]. Further, participation in these races has increased exponentially during the last 3 decades, with 2000 finishers accounted in 2008 for 161-km races in North America and $\sim 3$ races per year finished by each individual between 1977 and 2008 [12]. Commonly, the majority of these events are continuous races (i.e., single stage where athletes run a specific distance over a specific uninterrupted time); though, more recently, multi-day UTR races have been developed to further challenge the athletes involved.

Following this growth in popularity, UTR received the attention of the research community and a number of studies on the physiological and biomechanical changes associated with UTR were
1.9 per runner and 13.1 per 1000 -h run. Medical illnesses were the most prominent medical diagnoses encountered (50.3\%), followed by musculoskeletal injuries (32.8\%), and skin-related disorders (16.9\%). Despite the ultra-long nature of the race, the majority of injuries/illnesses were minor in nature. Medical staff and runners should prepare to treat all types of injuries and illnesses, especially the fatigue arising throughout the course of an ultratrail run and injuries to the lower limbs. Future studies should attempt to systematically identify injury locations and mechanisms in order to better direct injury prevention strategies and plan more accurate medical care. published $[5,19,21,28,29]$. This is because these types of events may permit the investigation and greater understanding of the limits of human performance [17]. However, very few data exist regarding the injuries and illnesses experienced by UTR athletes. Krabak et al. [14] described the injury/illness rates in 396 runners competing in 7-d, staged, 240-km UTR, reporting that the overall injury/illness rate was 3.8 per runner and 65 per 1000 -h run, mostly due to skin-related disorders involving the foot. The same findings were observed by Scheer and Murray [22], who studied 69 athletes competing in a 219-km, multiday UTR, noting a total of 99 medical encounters, mostly due to foot blisters (33.3\%) and chafing (9.1\%).

To our knowledge, no study has evaluated injuries/illness among continuous UTR (cUTR), which may limit the understanding both of injury/illness rates and potential risk factors during CUTR (as the 65-km cUTR supporting this study). This information may allow UTR athletes to appreciate the risk of participating in these races, and medical services can be coordinated more efficiently based on these parameters. 
Therefore, the purpose of the present study was to analyse and characterise injury/illness rates in runners competing in a cUTR. Specifically, we were interested in documenting the severity, type, and areas of injuries/illnesses during the race.

\section{Material and Methods}

$\nabla$

\section{Race characteristics}

The Vigolana Trail ${ }^{\circledR}$ is a cUTR that took place in June 2014 in Vigolo Vattaro (Trento, Italy). The course is $65 \mathrm{~km}$ long over rough terrain at medium altitude (altitude range between 725 and $2100 \mathrm{~m}$ ), with a total positive/negative elevation of $+4000 \mathrm{~m}$.

\section{Participants}

Participants competing in this race are primarily experienced runners who have completed marathons or other ultraendurance events as noted in their race application. One month before the start of the race, all participants registered received from the race organiser an email describing the study and encouraging participation. At the meeting the day before the race, 3 authors (G.V., A.S., and L.B.) reviewed the study with the interested participants. Further, the medical representatives of the race received a booklet with detailed information about the study, including the injury and illness forms to be filled out. All participants enrolled in the study gave their voluntary, written informed consent for their medical and race information to be used for research purposes. A participant was excluded from the study if he/she was under 18 or over 90 years of age, pregnant, or was unable to understand the consent form owing to a language impairment in reading/speaking Italian. An injury was defined as any new onset of pain or discomfort reported by the athletes that was related to the cUTR.

\section{Procedures}

As soon as the study participants crossed the finish line (time interval between the participant's arrival and the interview was $<10 \mathrm{~min}$ ), they were invited to present to the finish-line medical tent staffed by a physician whether or not they needed a medical encounter for an injury or illness. The medical staff documented each self-reported medical concern with a study participant using a standardized form noting diagnosis, site of injury, severity of the injury or illness. Then, members of the research group collected the injury data forms from the medical finish-line tent and all the information was entered into a computerized data registry for further analysis.

An injury/illness was defined as a disability sustained by a study participant during the race [14]. All injuries/illnesses were classified by their effect on the racers' ability to continue in the race: major, if the participant could not continue in the race; or minor, if the participant was able to continue in the race [14]. Each medical encounter was classified as an illness, a musculoskeletal (MSK) injury, or a skin disorder [14]. All information was treated strictly confidentially and the injury reports were made anony- mously according to the IJSM's ethical standards document [9]. Approval was obtained from the institutional Ethics Committee.

\section{Statistical analysis}

We defined a rate of injury/illness as the number of injuries/illnesses per 1000 runners and per $1000 \mathrm{~h}$ run [30]. We calculated an overall injury/illness rate and $90 \%$ confidence intervals (CIs), as well as rates for major and minor illnesses, MSK injuries, and skin disorders. Then, absolute and relative values were calculated from information contained in the returned questionnaires. $\mathrm{A} \chi^{2}$ test was used to compare all the categorical variables. A $\mathrm{z}$ test based on the Poisson model was used to compare both the number of injuries and health problems incidence per race event and the intra-race differences. The software IBM ${ }^{\circledR}$ SPSS $^{\circledR}$ Statistics (version 20.0.0, IBM Corp., Somers, NY, USA) was used and the $\alpha$-level was set at 0.05 .

\section{Results}

$\nabla$

Of the 234 runners who started the race, 204 (87.2\%) completed the cUTR. 85 runners agreed to take part in the study. 77 (37.7\% of the overall finishers) of the 85 (90.6\%, 13 females and 64 males) initially enrolled participants completed the cUTR and were interviewed ( $\odot$ Table 1 ). Because of the study design applied, it was impossible to interview the 8 participants who did not complete the cUTR. The mean time for completing the $65-\mathrm{km}$ race was $10 \mathrm{~h} 02 \mathrm{~min}$ (range $=6 \mathrm{~h} 58 \mathrm{~min}$ to $15 \mathrm{~h} 41 \mathrm{~min}$ ).

Table 1 Athletes' anthropometric and training characteristics. Data are presented as mean \pm standard deviation or in absolute and relative values.

\begin{tabular}{|ll|}
\hline Variable & 77 \\
\hline Sample size & $43.6 \pm 10.9$ \\
\hline Age (yrs) & $68.8 \pm 10.1$ \\
\hline Body mass (kg) & $1.75 \pm 0.08$ \\
\hline Height (m) & $10.02 .40 \pm 1.34 .51$ \\
\hline Performance time (h.min.s) & $11.0 \pm 10.2$ \\
\hline Running experience (yrs) & $3.8 \pm 3.3$ \\
\hline Trail running experience (yrs) & \\
\hline Number of trails completed (overall) & $24(31.2 \%)$ \\
\hline$<5$ & $16(20.8 \%)$ \\
\hline $5-10$ & $36(46.8 \%)$ \\
\hline$>10$ & $49(63.6 \%)$ \\
\hline Number of trails completed (2014) & $23(29.9 \%)$ \\
\hline$<5$ & $4(5.2 \%)$ \\
\hline $5-10$ & $53(68.8 \%)$ \\
\hline$>10$ & $46(86.8 \%)$ \\
\hline Training monitoring & $27(50.9 \%)$ \\
\hline Yes & $42(79.2 \%)$ \\
\hline Global Positioning System & $43(31.2 \%)$ \\
\hline Heart rate &
\end{tabular}

\begin{tabular}{lrc} 
Type of illness or injury & $\boldsymbol{n}$ & Rate per $\mathbf{1 0 0 0}$ runners $\mathbf{( 9 0} \% \mathbf{C l})$ \\
\hline All & 132 & $1885.7(1716.0-2338.3)$ \\
\hline Medical & 67 & $957.1(871.0-1186.8)$ \\
MSK & 43 & $614.3(559.0-761.7)$ \\
Skin & 22 & $314.3(286.0-389.7)$
\end{tabular}

Table 2 Injury/illness rates among ultratrail runners. 
A total of 132 injuries/illnesses were encountered during the races. These injuries/illnesses represented an overall injury/illness rate of 1885.7 per 1000 runners and 13.1 per $1000 \mathrm{~h}$ running. No injury/illness was classified as major. For the minor diagnoses, the majority of encounters were due to medical illnesses (50.3\%), followed by MSK injuries (32.8\%), and skinrelated disorders (16.9\%) ( $\bullet$ Table 2 ).

As shown in Table 3, for the medical illnesses, the majority were related to general fatigue $(37.7 \%)$, followed by muscle cramps (26.2\%). For the MSK injuries, ankle sprain (28.6\%), and plantar fasciitis (28.6\%) were the most common. Most skin disorders involved foot blisters (53.8\%).

\section{Discussion}

$\nabla$

Before preventive measures can be suggested, injury risk factors and mechanisms need to be characterised [26]. Surveillance systems established in other sports such as football [4], athletics [1], and the Olympics [6] have provided important information of injury risk and injury patterns. However, there is very little data regarding the injury and illness rates in UTR despite, for instance, the exponential increase in 161-km UTRs in North America between 1977 and 2008 [10,12]. To our knowledge, the current study is the first to report injury/illness rates in a $65-\mathrm{km}$ cUTR. Our overall injury/illness rate was 1.9 per runner and 13.1 per 1 -h run. All were minor in nature, mostly due to medical issues involving general fatigue experienced by the runners, followed by skin disorders and MSK injuries. Previous studies on ultramarathon runners have reported lower MSK injury rates (0.4-2.7 injuries per runner) $[2,7,8,13,14,22]$ compared with our finding of 4.3 MSK injuries per runner. Of these, only 2 studies reported skin or medical illness rates. Krabak et al. [14] reported that the skin disorders and medical illness rate were 2.7 and 0.3 per runner, respectively, after the $250-\mathrm{km}$ Racing The Planet $^{\complement} 4$ Desert Series ultramarathon. Scheer and Murray [22] reported a 0.8 skin disorder rate and a 0.5 medical illness rate after a $219-\mathrm{km}$, multiday UTR in the southern Spain. Further, our results were higher when compared to studies of marathon running where it was reported an overall injury/illness rate of 18.925.5 per 1000 runners, a medical illness rate of 10.1-13.7 per 1000 runners, an MSK injury rate of 3.35 per 1000 runners, and a skin injury rate of 4.1 per 1000 runners $[3,15,20,24]$. This discrepancy may be due to a variety of factors relating to the environment, equipment, and reporting bias. Indeed, multiday UTR runners may experience more extreme terrain and temperatures compared with cUTR runners, and carry packs weighing e.g., 5-30 kg with gear and food that must be rationed throughout the course of the race. In contrast, cUTR runners may experience similar terrain (even if with a lower exposure) and typically carry much less gear and food. These different features may explain the differences reported between multiday UTR and cUTR, since differences in the off-road terrains and temperatures, the exposure time, the effects of carrying additional weight may influence the injury and illness rates during UTR. Almost half of the diagnoses involved medical illnesses, with the majority relating to general fatigue ( $\bullet$ Table 3 ). This is not surprising as a growing body of literature indicates that runners experience long-term fatigue after such events [5,19,21,29]. Further, a high incidence of muscle cramps (26.2\%) was encountered. This medical issue, though with a higher incidence than previously reported after a marathon race (6.1\%) [20] and a 219 -
Table 3 Medical encounters from the study participants $(n=77)$ classified by diagnosis.

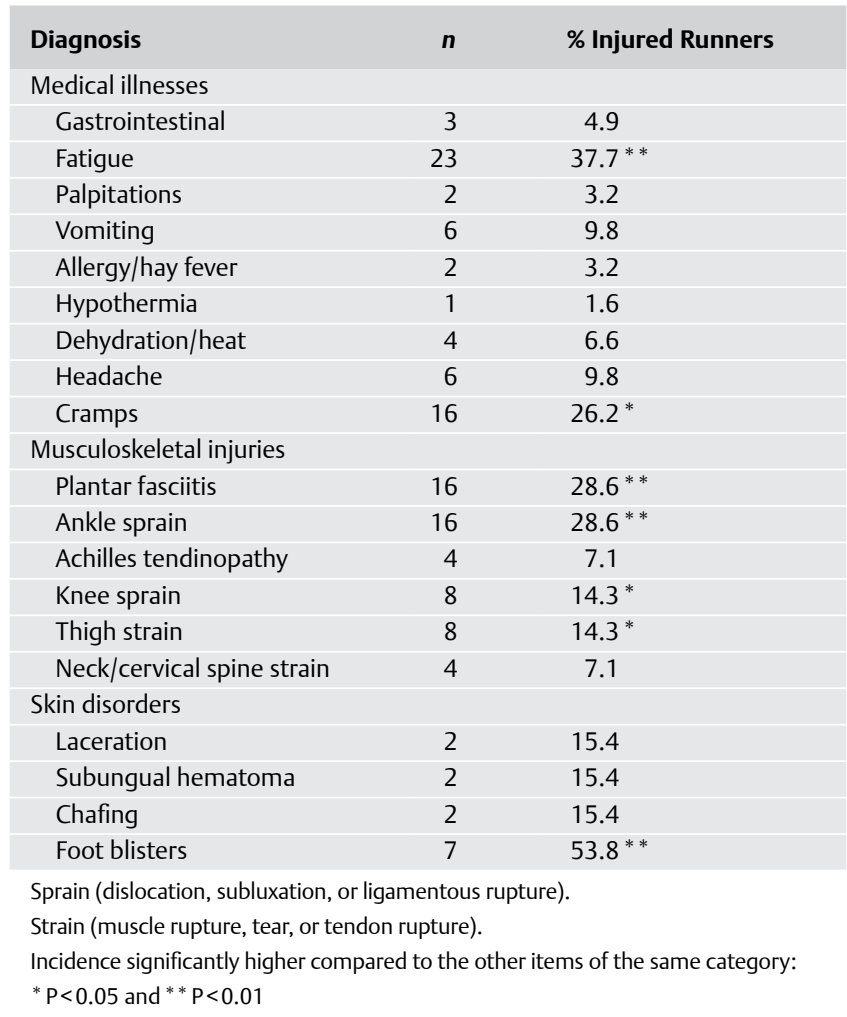

$\mathrm{km}$, multiday UTR (1.4\%) [22], is not surprising since it is well known that ultratrail running leads to the development of neuromuscular fatigue $[18,19,21]$, which appears to explain the onset of exercise-associated muscle cramping [23].

Approximately $33 \%$ of the diagnoses were due to MSK injuries, with ankle sprain and plantar fasciitis being the most common injuries ( $\odot$ Table 3). This observation paralleled the incidence of knee sprain and thigh strain (14.3\%) and is in line with the existing literature $[14,20,22]$. Though limited evidence exists to explain the risk factors for running injuries [25], postulated causes for MSK injuries during cUTR may include (i) the off-road nature of the cUTR that increases the chance for cumulative trauma to the lower limbs due to the terrain [14], (ii) number of repetitions of flexion and extension of the knee, as well as plantar and dorsiflexion of the ankle, (iii) duration of the cUTR that constrained the athletes to adopt a more shuffling type of gait, with a decreased joint range of motion [29], and (iv) excessive eccentric overload due to the downhill sections of the races [16]. Further, the higher incidence for MSK injuries observed in the foot is likely due to a greater demands on that structure from running ultra-long distances on irregular terrain [11].

Foot blisters were the most common dermatological complaint observed ( Table 3). This finding is not surprising since foot blisters are due to acute and continuous friction of both the shoes and socks against foot skin during running, likely exacerbated by the rough and hilly terrain in the context of UTR. This causes epidermal splits, with the separated layers then filling with blood or tissue transudate [15].

Finally, there are several limitations to consider in the current study. Fatigue was considered as physical and/or mental exhaustion that can be triggered by cUTR. Admittedly, with this definition we cannot know the contribution made by a medical illness or a normal post-cUTR experience. Future studies should inves- 
tigate the relative contribution of medical encounters and postrace experience on the sensation of fatigue. Because we reported only injuries/illnesses encountered after the race and not during the race, we could have underestimated the total number or severity of injuries/illness. This was because the medical checkpoint was positioned only at the finish-line medical tent and prevented us from gathering data on medical encounters from the non-finishers. Future studies should review the injuries/illnesses encountered both during and after cUTR. We did not analyse the effect of both gender and age on the risk of number of injuries/illnesses due the sample size and disproportionate number of male athletes and small variance in age. Future studies should analyse sex and age as potential risk factors for number of medical illnesses, MSK injuries, and skin disorders during cUTR. Finally, although the results of the present study suggest the most common injuries and illnesses experienced by $65-\mathrm{km}$ cUTR runners, data was gathered from a single event and a generalisation should be made with caution. Future studies should attempt to systematically identify injury locations and mechanisms in order to better direct injury prevention strategies and plan more accurate medical care during cUTR.

In conclusion, the results of this study suggest that despite the ultra-long nature of cUTR, the majority of injuries/illnesses experienced by runners are minor in nature. Medical staff and runners should prepare to treat all types of injuries and illnesses, especially the fatigue arising throughout the course of a cUTR and the lower limb injuries. Possible preventive strategies need to be explored further but could include educating runners regarding the types of injuries throughout the course of a cUTR. Further, this study provides useful information both to the (i) athletes, to direct their injury-prevention strategies, (ii) medical team, to provide adequate medical coverage, and (iii) researchers, to direct their focus to develop methods to prevent injuries.

\section{Acknowledgements}

$\nabla$

The authors want to thank the athletes for their cooperation. We are also in debt with Roberto Modena, Marco Sighele, and the medical staff for their technical contribution during the data collection. Finally, we would like to express our gratitude to Alberto Fondriest, Herbert Lorenzoni, Roberta Casagranda, and the Vigolana Trail ${ }^{\circledR}$ Organizing Committee. No support was provided for this study by any manufacturer of the instruments used. No conflicts of interest, financial or otherwise, are declared by the authors.

Conflict of interest: The authors have no conflict of interest to declare.

\section{Affiliations}

Department of Biomedical Sciences for Health, Università degli Studi di Milano, Milan, Italy

2Department of Neurological and Movement Sciences, Università degli Studi di Verona, Verona, Italy

CeRiSM, Research Center 'Sport, Mountain and Health', University of Verona, Rovereto (TN), Italy

${ }^{4}$ Department of Medical and Surgical Sciences, Università degli Studi di

Bologna, Bologna, Italy

\section{References}

1 Alonso JM, Edouard P, Fischetto G, Adams B, Depiesse F, Mountjoy M. Determination of future prevention strategies in elite track and field: analysis of Daegu 2011 IAAF Championships injuries and illnesses surveillance. Br J Sports Med 2012; 46: 505-514

2 Bishop GW, Fallon KE. Musculoskeletal injuries in a six-day track race: ultramarathoner's ankle. Clin J Sport Med 1999; 9: 216-220

3 Caselli MA, Longobardi SJ. Lower extremity injuries at the New York City Marathon. J Am Podiatr Med Assoc 1997; 87: 34-37

4 Dvorak J, Junge A, Derman W, Schwellnus $M$. Injuries and illnesses of football players during the 2010 FIFA World Cup. Br J Sports Med 2011; 45: 626-630

5 Easthope CS, Hausswirth C, Louis J, Lepers R, Vercruyssen F, Brisswalter $J$. Effects of a trail running competition on muscular performance and efficiency in well-trained young and master athletes. Eur J Appl Physiol 2010; 110: 1107-1116

6 Engebretsen L, Soligard T, Steffen K, Alonso JM, Aubry M, Budgett R, Dvorak J, Jegathesan M, Meeuwisse WH, Mountjoy M, Palmer-Green $D$, Vanhegan I, Renstrom PA. Sports injuries and illnesses during the London Summer Olympic Games 2012. Br J Sports Med 2013; 47: 407-414

7 Fallon KE. Musculoskeletal injuries in the ultramarathon: the 1990 Westfield Sydney to Melbourne run. Br J Sports Med 1996; 30: 319323

8 Fallon KE, Sivyer G, Sivyer K, Dare A. The biochemistry of runners in a 1600 km ultramarathon. Br J Sports Med 1999; 33: 264-269

9 Harriss DJ, Atkinson G. Ethical standards in sport and exercise science research: 2016 update. Int J Sports Med 2015; 36: 1121-1124

10 Hoffman MD. Performance trends in 161-km ultramarathons. Int J Sports Med 2010; 31: 31-37

11 Hoffman MD, Krishnan E. Health and exercise-related medical issues among 1,212 ultramarathon runners: baseline findings from the Ultrarunners Longitudinal TRAcking (ULTRA) Study. PLoS One 2014; 9: e83867

12 Hoffman MD, Ong JC, Wang G. Historical analysis of participation in $161 \mathrm{~km}$ ultramarathons in North America. Int J Hist Sport 2010; 27: 1877-1891

13 Hutson MA. Medical implications of ultra marathon running: observations on a six day track race. Br J Sports Med 1984; 18: 44-45

14 Krabak BJ, Waite B, Schiff MA. Study of injury and illness rates in multiday ultramarathon runners. Med Sci Sports Exerc 2011; 43: 2314-2320

15 Mailler EA, Adams BB. The wear and tear of 26.2: dermatological injuries reported on marathon day. Br J Sports Med 2004; 38: 498-501

16 Martin V, Millet GY, Martin A, Deley G, Lattier G. Assessment of lowfrequency fatigue with two methods of electrical stimulation. J Appl Physiol 1985 2004; 97: 1923-1929

17 Millet GP, Millet GY. Ultramarathon is an outstanding model for the study of adaptive responses to extreme load and stress. BMC Med 2012; 10: 77

18 Millet GY, Lepers R, Maffiuletti NA, Babault N, Martin V, Lattier G. Alterations of neuromuscular function after an ultramarathon. J Appl Physiol 1985 2002; 92: 486-492

19 Millet GY, Tomazin K, Verges S, Vincent C, Bonnefoy R, Boisson RC, Gergele L, Feasson L, Martin V. Neuromuscular consequences of an extreme mountain ultra-marathon. PLoS One 2011; 6: e17059

20 Roberts WO. A 12-yr profile of medical injury and illness for the Twin Cities Marathon. Med Sci Sports Exerc 2000; 32: 1549-1555

21 Saugy J, Place N, Millet GY, Degache F, Schena F, Millet GP. Alterations of neuromuscular function after the world's most challenging mountain ultra-marathon. PLoS One 2013; 8: e65596

22 Scheer BV, Murray A. Al Andalus Ultra Trail: an observation of medical interventions during a 219-km, 5-day ultramarathon stage race. Clin J Sport Med 2011; 21: 444-446

23 Schwellnus MP. Muscle cramping in the marathon: aetiology and risk factors. Sports Med 2007; 37: 364-367

24 Tang N, Kraus CK, Brill JD, Shahan JB, Ness C, Scheulen JJ. Hospitalbased event medical support for the Baltimore Marathon, 2002-2005. Prehosp Emerg Care 2008; 12: 320-326

25 van Gent RN, Siem D, van Middelkoop M, van Os AG, Bierma-Zeinstra $S M$, Koes $B W$. Incidence and determinants of lower extremity running injuries in long distance runners: a systematic review. Br J Sports Med 2007; 41: 469-480 discussion 480

26 van Mechelen W, Hlobil H, Kemper HC. Incidence, severity, aetiology and prevention of sports injuries. A review of concepts. Sports Med 1992; 14: 82-99 
27 Vernillo G, Rinaldo N, Giorgi A, Esposito F, Trabucchi P, Millet GP, Schena $F$. Changes in lung function during an extreme mountain ultramarathon. Scand J Med Sci Sports 2014, doi:10.1111/sms.12325

28 Vernillo G, Savoldelli A, Zignoli A, Skafidas S, Fornasiero A, La Torre $A$, Bortolan L, Pellegrini B, Schena $F$. Energy cost and kinematics of level, uphill and downhill running: fatigue-induced changes after a mountain ultramarathon. J Sports Sci 2015; doi:10.1080/02640414 .2015.1022870 1-8
29 Vernillo G, Savoldelli A, Zignoli A, Trabucchi P, Pellegrini B, Millet GP, Schena $F$. Influence of the world's most challenging mountain ultramarathon on energy cost and running mechanics. Eur J Appl Physiol 2014; 114: 929-939

30 Videbaek S, Bueno AM, Nielsen RO, Rasmussen S. Incidence of runningrelated injuries per $1000 \mathrm{~h}$ of running in different types of runners: a systematic review and meta-analysis. Sports Med 2015; 45: $1017-$ 1026 